\title{
Some Thoughts Concerning the Education of Refugee Children
}

\author{
by Marcela Durán
}

The history of the education of immigrants and refugees in Canada parallels the country's history of immigration and is as diverse and complex. Traditionally, immigrant communities have received a mixed welcome from the resident population. The reception of their children into Canadian schools has echoed those public attitudes. ${ }^{1}$

On many occasions in the past, minority communities had to take matters in their hands to ensure that their children received the kind of education they felt was necessary for their spiritual, cultural and economic survival. In the Province of Ontario, examples include the creation of the Separate Catholic School Board in the last century to respond to the needs of Irish Catholic Immigrants ${ }^{2}$ and the establishment of separate schools for Black children. Among the latter, the case of the children of fugitive American Black slaves, who arrived in Ontario during the mid 1800 s as refugees via the underground railroad, serves as a timely illustration of refugee education. Fugitive slaves were invited to Canada and arrived through the efforts and support of many Canadians. The social reception for these refugees was, nevertheless, an uneasy one. The conflicts over schooling for

\footnotetext{
1 Mary Ashworth, Blessed with Bilingual Brains: Education of Immigrant Children with English as a Second Language (Vancouver: Pacific Educational Press, 1988).

${ }^{2}$ Murrray W. Nicholson, "Irish-Catholic Education in Victorian Toronto: An Ethnic Response to Urban Conformity", Histoire Sociale-Social History, XVII, No. 34 (November-December 1984), pp. 287-306.
}

their children ended up being resolved by regulations that created separate schools in some areas. ${ }^{3}$ Having to educate their children in segregated schools or having to cope with racism in nonsegregated schools caused great grief

\section{The ability to speak English or French with the receiving population and insti- tutions to provide good quality educa- tion and freedom of religious observance for their children. ${ }^{4}$} was the criterion for school placement. Many of the European refugees found themselves sitting in grade one classes at 10 or 11 years of age, in spite of the fact that they were in higher grades in their home countries.

amongst the refugee community. It certainly added to their adjustment difficulties.

${ }^{3}$ Susan E. Houston and Alison Prentice, Schooling and Scholars in Nineteenth-Century Ontario (Toronto: University of Toronto Press, 1988), pp. 296-302.
The education of Jewish children in Canada is again a difficult and in many instances, as in the case of "The Jewish School Question in Montréal" that lasted for almost a century, a harrowing example of how a community of exiles and refugees has had to struggle and debate

\section{Post World War II}

In a more recent example, the migrations that followed the end of World War II were primarily movements of refugees, exiles and displaced people despite the fact that they may have been classed as immigrants.

The immigrants arrived into a more mature nation which had developed strong school systems in each province. Based on receiving immigrants during the first three decades of the 20th century, there had developed a national a "superior Canadianizing agency".

The children from the postwar migrations have told their stories in many forms. Their bittersweet memories of school days in Canada can be interpreted as combining the natural difficulty of adjusting to a new society while encountering prejudice and racism in school yards and classrooms. Their teachers interpreted their mission as one of turning these children into

1 Blessed with Bilingual Brains, pp. 5-9. mood and agreement that schooling was 


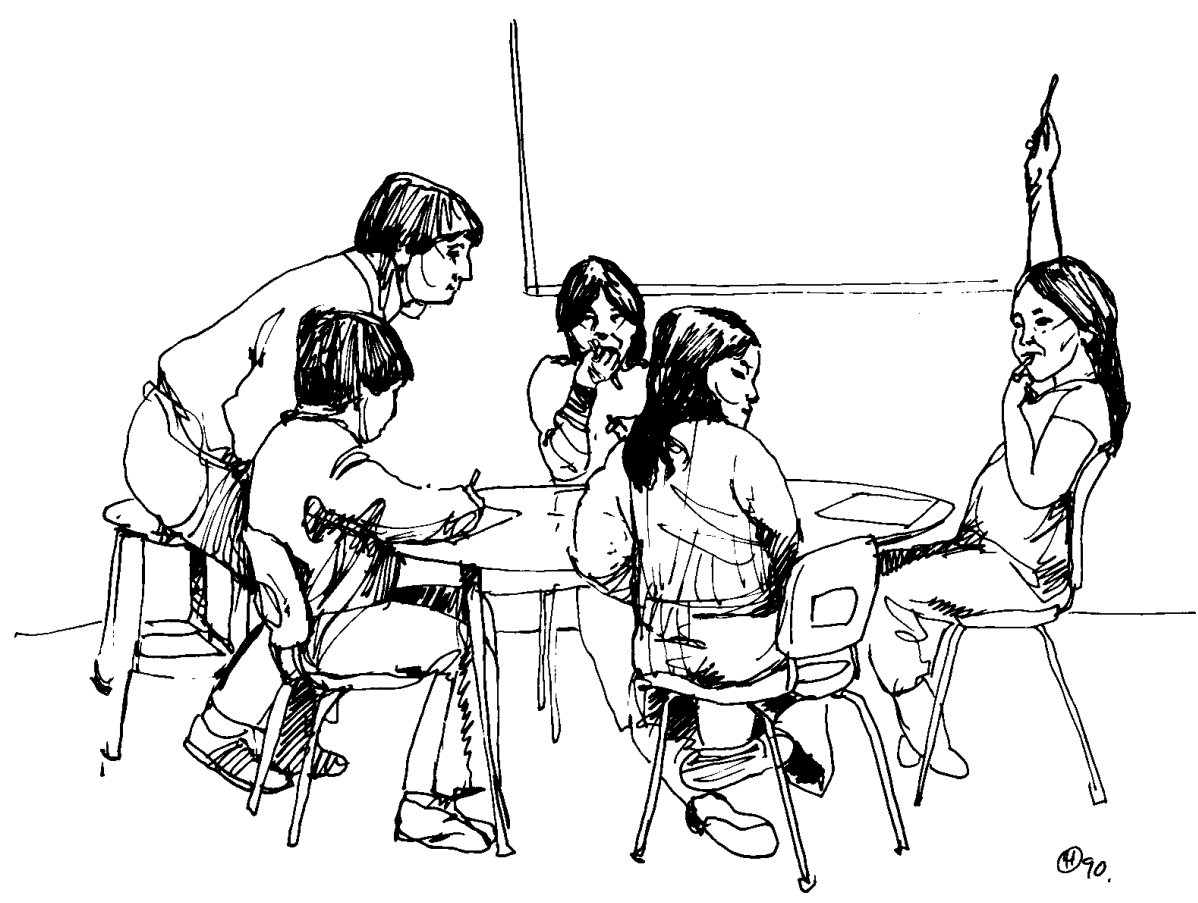

good law-abiding Canadians as soon as possible.

In English-speaking Canada this meant becoming as Anglo as you possibly could and as soon as you could. Schooling was mostly a subtracting and replacement type of experience: Subtract the first language. Subtract the customs and mores. Subtract the experiences. Replace them with the new language, new mores, new customs, new ways of communicating in the home. Well-meaning teachers and administrators would advise parents to stop speaking the language with which they had been raised and replace it with English as "this would give their children a better start."

The ability to speak English or French was the criterion for school placement. Many of the European refugees found themselves sitting in grade one classes at 10 or 11 years of age, in spite of the fact that they were in higher grades in their home countries. Most of the learning depended on the newcomer's capacity to absorb new information, draw conclusions and make connections in the new language. There were few specialized English as a Second Language teachers, and many of the immigrants do not remember having had ESL teachers during their first few years in Canada.

The absence of ESL classes and placing children in grades well below the abilities of the students added to the traumas of war and refuge. Nevertheless, there were many good things that pulled these children through. For one, there was no overt public questioning of their right to be in school and of their right to belong. If there was, it did not result in legislation against them, as had been the case with Black and Jewish children in the past.

\section{The 1960s and 1970s}

The 1960s and 1970s saw a definite change, not only in the direction of immigration policy, but also of school policies related to minority groups.

The influence of developmental psychology and child-centered pedago- gies contributed in stopping schools from placing older immigrant children in grades for younger children. English or French as Second Language classes for new Canadian children became a standard feature of schools in large urban centres. With them, grew a cadre of specialized teachers who understood the needs of newly arrived children, if not through their training, at least through their everyday exposure to their needs and questions. From a timid beginning in the late 1950s and 1960s, ESL teaching and teachers developed during the 1970 s to the point of creating a powerful association of teachers of ESL in Canada. ${ }^{5}$ ESL teachers hold national conferences where the needs of immigrant and refugee children are discussed openly and thoughtfully.

One could also credit the development of multicultural policies of the 1970s. Although strongly criticized for promoting endless eating, singing and folk dancing in schools, instead of a realistic intercultural education, multiculturalism in the schools did bring about a sense of acceptance of ethnicity and differences. All of a sudden, it became acceptable in many schools for children to speak their languages, eat their foods and keep their first names in their own language. Festivals in the schools integrating the new communities and translation services in interviews with parents also became a feature in the lives of many students.

Multiculturalism also stimulated and provided some funds to allow minority communities to organize centres and programs to maintain their culture and heritage. Of course, the communities had done so all along, but without official support.

Immigrant communities felt empowered to make presentations to local school authorities about the needs of their children. In some instances their presentations resulted in the inclusion of effective Heritage Language programs and the creation of committees to develop Race Relations policies.

${ }^{5}$ TESL Canada Federation/Federation TESL du Canada. 
The new Immigration Act and Refugee Policy of 1976 brought about a newly created national awareness with respect to refugees. Despite the fact that refugee children had been registering in Canadian schools since the 1800 s, the national sponsorship and arrival of the Vietnamese refugees brought a dramatic change in public perceptions as well as in school responses. For the first time, schools and communities everywhere became concerned with the educational needs of the Vietnamese children. The lesson learned since then have been a

\section{While progress} has been made during

the past decades, there are still many reasons to be concerned about the needs of refugee students. The concerns relate, on the one hand, to the experiences refugee students bring with them, and,

on the other hand, to the uneven delivery of services and related knowledge base existing in schools. force in the many changes in non-governmental organizations as well as in service delivery that touch the lives of refugees.

Race Relations policies during the 1980s added yet another new dimension to the complex combination of circumstances, policy making and change required to improve the educational opportunities of minority students.

\section{The 1980s and 1990s}

At this point, it would seem appropriate to ask ourselves if we should still be worrying about the education of refugees. Should we orient ourselves towards other areas of need, given all the progress we have witnessed in the provision of educational services for newcomers?

While progress has been made during the past decades, there are still many reasons to be concerned about the needs of refugee students.

The concerns relate, on the one hand, to the experiences refugee students bring with them, and, on the other hand, to the uneven delivery of services and related knowledge base existing in schools.

As another article in this issue demonstrates, the traumatic emotional baggage that refugees carry with them into the new society plays a significant role in their possibilities for successful adjustment and integration. Refugee students and their parents may have been subjected to prolonged persecutions in their home countries; to long and arduous journeys to refugee camps; to periods of life in those camps (stretching from a few months to many years); to difficult family relationships due to stress and insecurity, as well as to poor health, due to either life in camps or minimal medical and sanitary care. Refugee children and adolescents will have also experienced disrupted schooling and in some cases may not have been to school at all.

Upon arrival in Canada and during their first two years here, they will also experience a series of changes that can affect their possibilities for success in school: Culture shock and a difficult
Psychological

assessments could yield the wrong results if the assessors have not been educated in principles of immigrant and minority education. Unfortunately, much of the testing continues to be mechanistic. Many decisions continue to be based on IQ tests that are administered in English and do not take into consideration the specific needs of refugees.

transition to the new society, many changes of residence and hence of schools, anxiety, tiredness, poor health and also possibly rejection, racism and prejudice in schools and neighborhoods.

Are schools and teachers prepared to understand these realities in their students' backgrounds? In trying to answer similar questions, Mary Ashworth states: "The quality of the recep- 
tion, assessment and placement of ESL. students from preschool to senior secondary school, helps or hinders their academic progress and their success in integrating into school and community life. An insensitive reception, or an inadequate or faulty assessment, or a wrong placement, lays an unnecessary burden on a child struggling to begin a new life in a new land in a new language. While governments and school boards make policies, it is teachers who put them into practice - or, perhaps, circumvent them if they are detrimental to children." 6

Specialized reception procedures for refugee and immigrant students vary widely between provinces, as well as boards of education, and sometimes from school to school within one board. The assessment of educational background and school-related skills again varies widely depending on the school, city or province. While some boards provide for special assessments in first language to newly-arrived students, others do not. The same variation can be observed with regards to placement procedures. As a result, refugee students in Canada could be registering in schools where teachers and school administrators may be very skilled in understanding and attending to the emotional and academic needs of refugees. On the other hand, teachers and administrators may neither understand nor have the willingness and knowledge base to attend to their reception, assessment and placement needs.

From a critical perspective, the areas that require most attention, and that have been almost universally neglected in Canada in relation to the education of refugees, are assessment and teacher education.

Refugee students upon arrival need an educational assessment that will help the student and the school to find out what kinds of educational programs (ranging from literacy to credit options) the student needs. These assessments must take into consideration the refugee's background and experience

6lessed with Bilingual Brains, p. 138. as well as first language and schoolrelated skills. If the assessments are not conducted effectively, wrong decisions with regards to placement and school programs can result. A good assessment requires teachers or personnel who can speak the language of the student, who understand Second Language Acquisition theories and who are able to interpret the student's experiences in order to advise the classroom teacher or school administration on a program that will truly provide for the best education for that student.

The other area of concern, with regard to assessment, relates to possible requests by teachers for psychological

\section{While change} is observable in many boards of education, at least at the policy making level and in ESL teaching, very little seems to be happening in universities.

assessments when refugee students are not performing or progressing at the ratio of other students. Psychological assessments could yield the wrong results if the assessors have not been educated in principles of immigrant and minority education. Unless a school psychologist approaches the testing of a refugee student from a dynamic, holistic perspective, that takes into account the student's past traumatic experiences, second language acquisition and academic history, and contrasts this data with the history of the settlement process looking carefully at what kinds of programs the student has been exposed to in Canada, one could be pessimistic regarding the results or recommendations of such testing procedures. Unfortunately, much of the testing continues to be mechanistic. Many decisions continue to be based on IQ tests that are administered in English and do not take into consideration the specific needs of refugees.

The third area that should be of concern with regard to immigrant and refugee education is the slow change observed in teacher training institutions. While change is observable in many boards of education, at least at the policy making level and in ESL teaching, very little seems to be happening in universities. A cursory look at the curriculum of teacher training programs in Ontario shows that topics such as Second Language Acquisition, Bilingualism, Heritage Languages, Race Relations, CrossCultural Adaptation Theories, Minority Education and Anti-Racist Education are seldom included in the required courses for future teachers. There seems to exist little academic interest in these areas. In addition, a recently published study commissioned by the Ontario Ministry of Education shows that the majority of student teachers in Ontario universities do not represent the ethnic and racial diversity of the Province so clearly observable in the urban schools of Ontario. ${ }^{7}$

As a conclusion, we can be optimistic about the many changes that have happened in immigrant and refugee education in Canada. These changes ensure that a large number of the students will receive second language instruction from qualified and well trained ESL teachers. However, we cannot be equally optimistic due to the lack of change in other areas, namely reception, assessment and classroom teacher training, which are crucial to the academic survival and success of refugee students.

Marcela Durán teaches at the Faculty of Education at York University.

\footnotetext{
${ }^{7}$ Laverne Smith, Perspectives on Teacher Supply and Demand in Ontario, 1988-2008 (Toronto: Ontario Ministry of Education, 1989).
} 